\title{
Influence of Novel Redirector with Bypass Damping on the Performance of Load-Sensing Steering System
}

\author{
Yuqi Wang, Xinhui Liu, Jinshi Chen ${ }^{*}$ and Dongyang Huo
}

\begin{abstract}
Load-sensing steering systems for articulated loaders are prone to large pressure shocks and oscillations during steering operations, affecting the system stability. An optimized structure of the redirector with bypass damping is proposed to improve this phenomenon. In this structure, orifices and throttle grooves are added to the traditional redirector. To control the steering load and working conditions, the steering load of the loader is replaced by a pressure regulating valve. Simulation and experimental results reveal that the redirector with bypass damping has better load-sensing characteristics than the traditional redirector. The peak output pressure shock caused by the load unit step signal decreases from 6.50 to $5.64 \mathrm{MPa}$, which means the pressure oscillation of the hydraulic system is reduced by $13.4 \%$. The pressure fluctuation time can be reduced from 2.09 to $1.6 \mathrm{~s}$, with a decrease rate of $23.4 \%$. The output pressure oscillation decays swiftly, and the smoothness of the steering operation is improved significantly.
\end{abstract}

Keywords: Articulated vehicle, Redirector, Load-sensing steering system, Pressure oscillation

\section{Introduction}

A loader is mainly used to load and unload materials and shovel work within a certain range, and frequent steering operations are required in its working conditions $[1,2]$. Researchers have conducted comprehensive studies on steering systems for articulated vehicles using numerical analysis and simulations [3-5]. More accurate steering performance and the main parameters affecting the performance have been obtained. During the steering operation of existing articulated loaders, some unstable situations, such as shocks and oscillations in the hydraulic system, have occurred, resulting in poor machine stability of the machine when steering starts and stops. The higher the steering wheel speed, the more obvious the shaking or shimmy of the fuselage $[6,7]$.

The optimization of steering system performance has also become a focus of research. In Ref. [8], the NSGA-II

*Correspondence: spreading@jlu.edu.cn

School of Mechanical and Aerospace Engineering, Jilin University, Jilin 130022, China algorithm was used to optimize the steering system to improve the performance of the system further. A novel steering system was developed to improve the driving performance during steering [9]. Other researchers [10, 11] optimized the articulated frame to obtain a more compact articulated frame steering system and improve the steering flexibility.

For an unstable hydraulic system, the introduction of a steering system with independent control of the inlet and outlet ports was found to improve the steering stability and sensitivity under high torque [12]. Load-sensing [13], proportional variable [14], and other variable displacement pumps have been used to replace the fixed displacement hydraulic pump for single-rod [15-17] and double-rod [18] hydraulic cylinder steering systems and to build a closed-loop steering system. The displacement of the pump was controlled by the rotation speed of the steering wheel, which means that oil could be supplied on demand. This reduced the loss and improved the stability of the steering system. Yang et al. [19] proposed an automatic steering system in which a DC motor is directly 
connected to a full hydraulic redirector. It improves the steering accuracy and simplifies operation. To ensure steering operation safety, frequency conversion speed regulation technology was combined with a full hydraulic redirector system $[20,21]$ to develop and improve a frequency conversion hydraulic redirector [22-24]. Appropriate structures and control strategies have been designed to overcome the nonlinear factors that affect the power performance of redirectors. Furthermore, a more effective use of the redirector energy was realized, and the robustness of the system was improved [25-27]. A steering scheme for installing a bypass proportional throttle valve on the outlet of a fixed displacement hydraulic pump was proposed [28].

To some extent, previous research has alleviated the pressure shock, oscillation, and other instabilities of articulated vehicles during steering caused by oil supply pressure. However, it remains difficult to control the pressure shock caused by sudden flow changes, and the steering system still exhibits large oscillation under highspeed conditions. To address the problems of the hydraulic system, a redirector structure with bypass damping was designed in this study.

The remainder of this article is organized as follows. In Section 2, the working principle of the redirector with bypass damping is introduced. In Section 3, the relationship between the valve port area and the control spool displacement of the redirector is deduced, and a mathematical model is established. Moreover, the interaction among the flow rate, pressure, and rotation speed of the redirector is described in detail. In Section 4, a simulation model of the redirector with bypass damping established to verify the performance is described, and the simulation results obtained are presented. An experimental simulation platform is described in Section 5, and the effectiveness of the redirector with bypass damping is evaluated based on the experiments. In Section 6, the dynamic characteristics and oscillation are analyzed, along with the differences and similarities between the novel and traditional redirectors. Finally, Section 7 concludes the article.

\section{Working Principle}

The research object in this study is a coaxial flow rate amplification redirector, whose structure is shown in Figure 1(a). It is mainly composed of three parts: housing, metering motor, and rotary valve (including the control spool and control sleeve). The control spool of the redirector is connected to the steering wheel, and rotates thereby turning the steering wheel. There is a relative angular displacement between the control spool and the control sleeve. The input P opens after the control spool

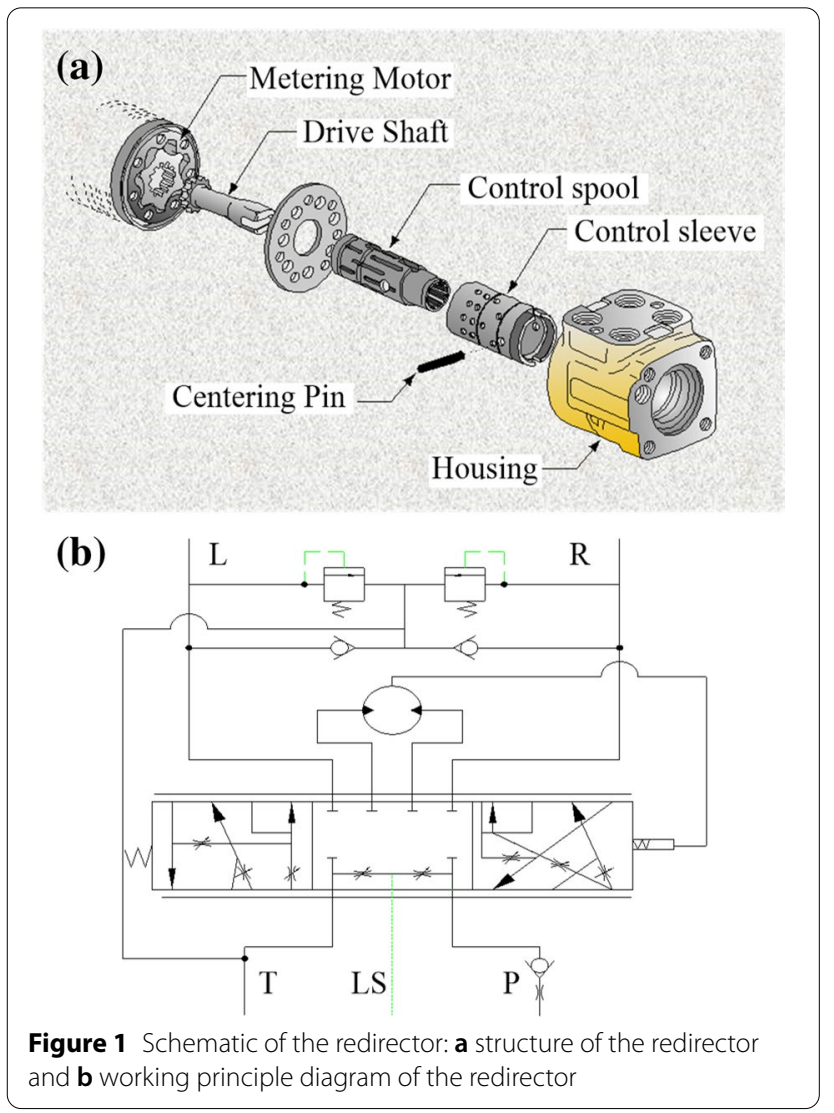

rotates at a certain angle. The fluid enters through the input and pushes the metering motor to rotate.

The metering motor is mainly used to ensure that the flow rate of the oil delivered by the redirector is proportional to the steering wheel angle when the steering pump is working. If the steering pump is not working, the motor directly sucks oil from the oil tank and supplies it to the steering cylinder when rotating the steering wheel. The relative angular displacement of the control spool and control sleeve increases when the rotation speed of the steering wheel increases. The flow rate and steering speed both increase in the meantime.

Figure 1(b) shows a diagram of the working principle of the redirector. When the redirector is in the medium position, port $\mathrm{P}$ and the bypass damping hole are disconnected from ports $\mathrm{R}$ and $\mathrm{L}$. The oil enters the channel through ports $\mathrm{P}$ and LS and returns to the tank through port $\mathrm{T}$. The left and right position switches of the redirector are consistent with the rotation direction of the steering wheel. When the steering wheel rotates at high speed, the steering rod drives the control spool to rotate at a large angle. The oil enters the channel through flow rate amplification holes and is directly output from parts $\mathrm{L}$ and $\mathrm{R}$ of the redirector of the steering cylinder to complete the steering. Port $\mathrm{R}$ or $\mathrm{L}$ is connected to port 
$\mathrm{T}$ through the bypass throttle hole $\mathrm{K}$ when the steering wheel rotates; thus, the pressure shock and oscillation caused by the displacement of the cylinder can be reduced by bypass damping to achieve smooth steering.

\section{Methodology and Model}

\subsection{Calculation of the Opening Area}

The rotary valve comprises a control spool with four groups of grooves and a control sleeve with 10 groups of through holes. When the control spool rotates, the direction and flow rate of the oil are changed by the on-off and opening areas of different grooves and through holes, as shown in Figure 2(a).

The through holes on the control spool are evenly distributed along the circumference, and 12 holes in each of $\mathrm{P}$ and $\mathrm{H}$ are distributed along the same centerline. Holes $\mathrm{H}$ are numbered from left to right, odd columns are aligned with the centerline of holes L, and even columns are aligned with the centerline of holes $\mathrm{R}$. The positions of the bypass damping holes $\mathrm{K}$, holes LS, and flow rate amplification holes are shown in Figure 2, and the other through holes are $\mathrm{T}$. There are six channels in each of A, B, C, and D on the control sleeve distributed along the circumference. Channel A controls the on-off of L-T or R-T. Channel C controls the on-off of P-T and feedback of LS. Channel B is evenly distributed between channels $A$ and $C$ to control the on-off of R-H or L-H and realize flow rate amplification performance. Channel D controls the on-off of L-K or R-K.

It is necessary to calculate the opening area of each port and channel when examining the performance of the redirector. For the convenience of calculation, the assembly of the control spool and control sleeve along the axis is expanded, as shown in Figure 2(b). The channel portion of the control sleeve is indicated by solid lines, and the control spool portion is indicated by dotted lines.

The oil flow path of the redirector is divided into seven modules. The opening area of the inlet module, $\mathrm{P}-\mathrm{C}$, is

$$
A_{P}= \begin{cases}3 r^{2}(\theta-\sin \theta) & (0<x<2 r), \\ 6 \pi r^{2} & (2 r<x),\end{cases}
$$

where $\theta=2 \arccos \frac{r-x}{r}, r$ is the diameter of the hole, and $\theta$ is the angle corresponding to the opening area.

The opening area of the flow rate amplification module A-C is

$$
A_{P A}=\left\{\begin{array}{lr}
9 r^{2}(\theta-\sin \theta) & \left(0<x<x_{1}\right), \\
6 r^{2}(\theta-\sin \theta)+\left(\frac{3}{2} \theta+1.02\right) r^{2} & \left(x_{1}<x<x_{2}\right), \\
-1.5 r^{2} \sin \theta-3(r-x) & \\
18 \pi r^{2}\left(\frac{3}{2} \theta+1.02\right) r^{2} & \\
-6 r^{2}(\theta-\sin \theta)+18 \pi r^{2} & \left(x_{2}<x\right), \\
-1.5 r^{2} \sin \theta-3(r-x) &
\end{array}\right.
$$

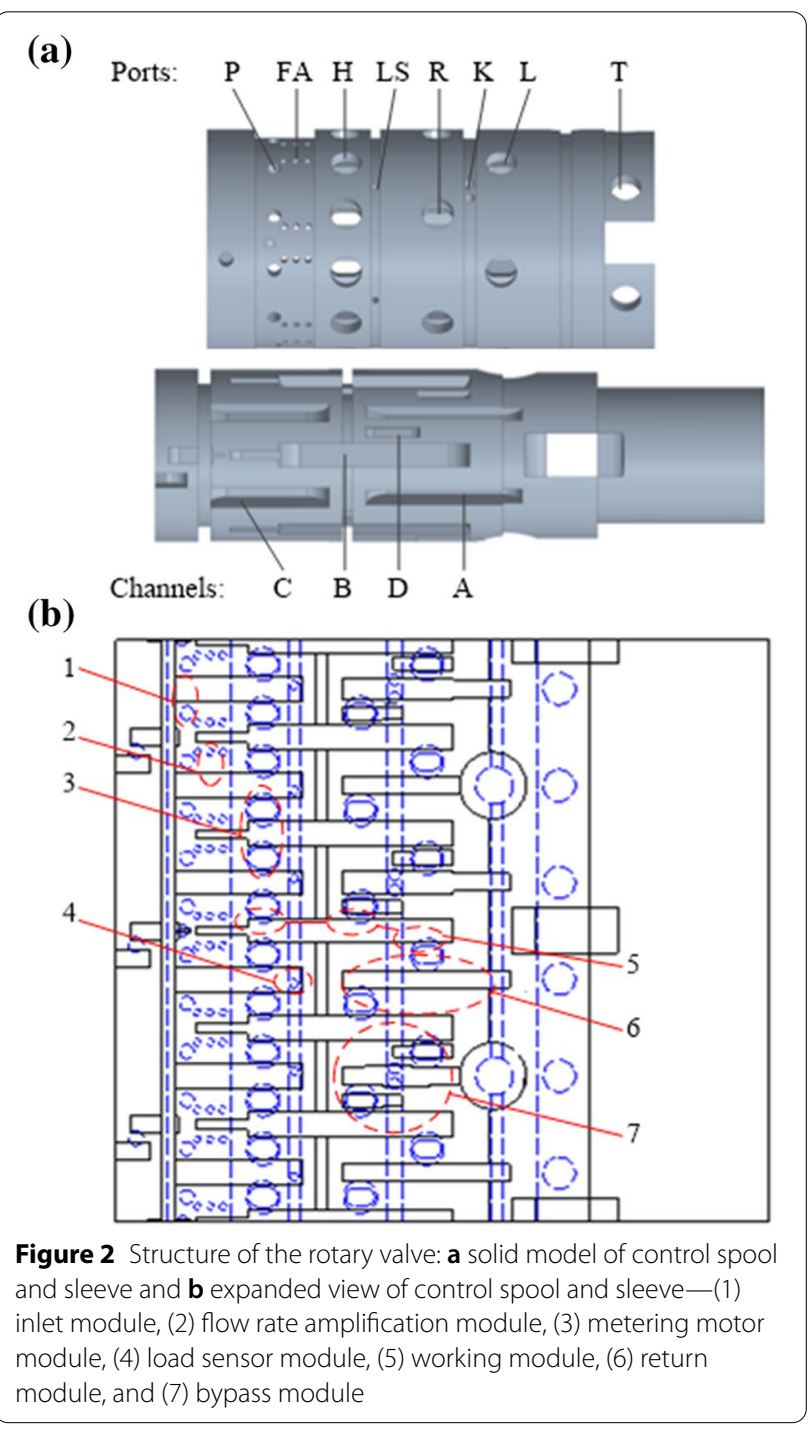

where $x_{1}$ and $x_{2}$ are displacements of two limit positions.

The opening area of the metering motor module when the oil passes through inlet and outlet $\mathrm{H}$ of the metering motor is

$$
A_{H}= \begin{cases}1.5 r^{2}(\theta-\sin \theta)+3 x l & (0<x<2 r), \\ 3 r(l+\pi r) & (2 r<x),\end{cases}
$$

where $l$ is the side length of the motor hole.

The opening area of the working module $H-R \backslash L$ is

$$
A_{R \backslash L}= \begin{cases}3 r^{2}(\theta-\sin \theta)+6 x l & (0<x<5 r), \\ 6 r(2 l+\pi r) & (5 r<x) .\end{cases}
$$

The opening area of the return module $\mathrm{R} \backslash \mathrm{L}-\mathrm{T}$ is 


$$
A_{T}= \begin{cases}r^{2}(\theta-\sin \theta)+2 x l & (0<x<a), \\ r^{2}(\theta-\sin \theta)+6 x l & (a<x<2 r-a), \\ +2 r^{2}\left(\theta_{1}-\sin \theta_{1}\right) & \end{cases}
$$

where $\theta_{1}=2 \arccos \frac{r-x+a}{r}$.

The opening area of the load sensor module when oil passes through L-S is

$$
A_{L S}= \begin{cases}6 \pi r^{2} & (x<a), \\ 6 \pi r^{2}-\frac{3}{2} r^{2}(\theta-\sin \theta) & (a<x<a+l), \\ 3 \pi r^{2}-\frac{3}{2} r^{2}(\theta-\sin \theta) & (a+l<x<a+l+2 r), \\ 0 & (a+l+2 r<x),\end{cases}
$$

where $a$ is the transverse distance of opening area.

The opening area of the bypass module $\mathrm{R} \backslash \mathrm{L}-\mathrm{D}$ is

$$
A_{D}= \begin{cases}3 l(a-x)+\frac{3}{2} r^{2}(\theta-\sin \theta) & (0<x<a), \\ 0 & (a<x) .\end{cases}
$$

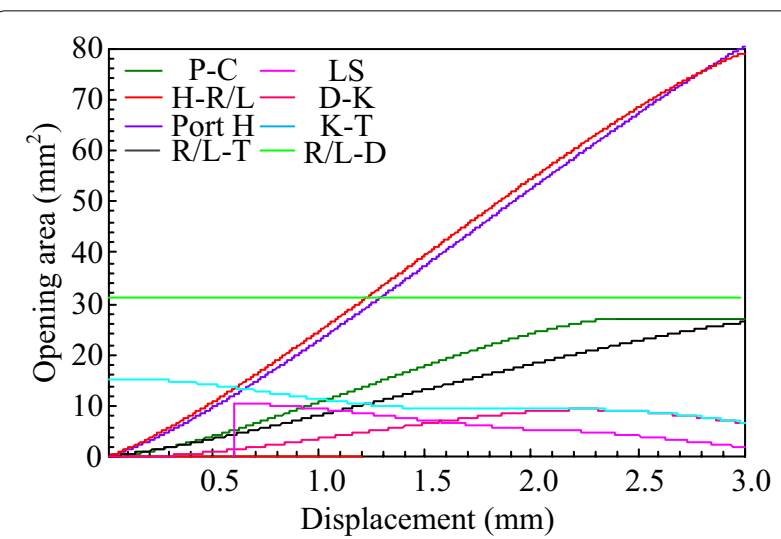

Figure 3 Relation between the opening area of each module and the control spool displacement

the structure and working principle of the redirector is shown in Figure 4.

The combination of the metering motor seal oil cavity

$$
A_{D-K}= \begin{cases}\frac{1}{2} r^{2}(\theta-\sin \theta) & (0<x<a), \\ \frac{1}{2} r^{2}(\theta-\sin \theta)+r^{2}\left(\theta_{1}-\sin \theta_{1}\right) & (a<x<2 r), \\ \pi r^{2}+r^{2}\left(\theta_{1}-\sin \theta_{1}\right) & (2 r<x<l), \\ \frac{1}{2} r^{2}\left(\theta_{2}-\sin \theta_{2}\right)+r^{2}\left(\theta_{1}-\sin \theta_{1}\right) & (1<x<2 r+a), \\ \frac{1}{2} r^{2}\left(\theta_{2}-\sin \theta_{2}\right)+2 \pi r^{2} & (2 r+a<x<a+l), \\ \frac{1}{2} r^{2}\left(\theta_{2}-\sin \theta_{2}\right)+r^{2}\left(\theta_{3}-\sin \theta_{3}\right) & (a+l<x<l+2 r),\end{cases}
$$

where $\theta_{2}=2 \arccos \frac{x-r-l}{r}$, and $\theta_{3}=2 \arccos \frac{x-a-r-l}{r}$.

The opening area of the bypass module $\mathrm{K}-\mathrm{T}$ is

$$
A_{K}= \begin{cases}\frac{3}{2} r^{2}\left(\varphi_{1}-\sin \varphi_{1}\right) & \left(0<x<2 r-l_{2}\right), \\ +\frac{3}{2} r^{2}\left(\varphi_{2}-\sin \varphi_{2}\right) & \\ 3 \pi r^{2}+\frac{3}{2} r^{2}\left(\varphi_{1}-\sin \varphi_{1}\right) & \left(2 r-l_{1}<x<l_{1}\right), \\ 3 \pi r^{2} & \left(l_{1}<x<l_{3}\right), \\ \frac{3}{2} r^{2}\left(\varphi_{3}-\sin \varphi_{3}\right) & \left(l_{3}<x<2 r+l_{3}\right),\end{cases}
$$

where $\varphi_{1}=2 \arccos \frac{r+x-l_{1}}{r}, \varphi_{2}=2 \arccos \frac{r-x-l_{2}}{r}$, and $\varphi_{3}=2 \arccos \frac{x-l_{3}-r}{r}$. Here, $l_{1}$ and $l_{2}$ are the distances between two limit positions and two holes, and $l_{3}$ is the distance between the two holes.

The relationship curves between the opening area of each module and the control spool displacement are shown in Figure 3.

\subsection{Mathematical Model of the Redirector}

To further analyze the dynamic characteristics of the redirector with a bypass damping structure, a mathematical model of the redirector is established. The following assumptions are accepted, ignoring the pipeline loss, internal leakage, friction, and hydraulic force of the redirector, which have little effect on the steering performance. A schematic of the equivalent damping based on and the hole and channel structure of the rotary valve realizes the oil distribution relationship of the redirector. The flow rate continuity equation of the metering motor without considering leakage is

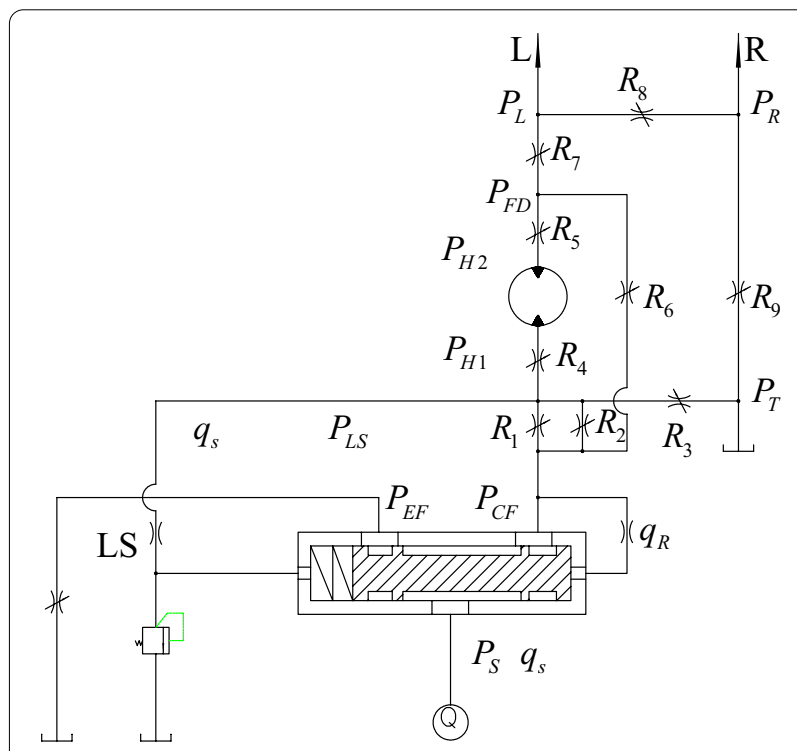

Figure 4 Schematic of the equivalent damping 


$$
q_{m}=D_{m} \dot{\theta}_{m}
$$

where $\dot{\theta}_{m}$ is the angular velocity of the motor, and $D_{m}$ is the displacement of the motor.

The redirector is mainly subjected to pressure distributed uniformly in the radial direction while working [29]. Because the control sleeve of the redirector is rigidly connected to the rotor of the motor, the force condition of the redirector is the same as that of the metering motor. According to the working principle of the redirector, the viscous friction and drag torque between the control sleeve and control spool of the rotary valve are the main loads of the motor. Viscous friction can be ignored because it is much smaller than the drag torque. The force balance equation of the motor is

$$
T_{l}=D_{m}\left(P_{H 1}-P_{H 2}\right),
$$

where $P_{i}$ is the pressure between the orifices in the rotary valve.

According to their axial direction, the control spool and control sleeve of the redirector are expanded into a planar structure. The displacement of the control spool is

$$
x_{z}=\frac{d}{2}\left(\int_{0}^{t} \omega_{f} \mathrm{~d} t-2 \pi \int_{0}^{t} \frac{q_{m}}{D_{m}} \mathrm{~d} t\right)=x_{z}\left(\omega_{f}\right),
$$

where $\omega_{f}$ is the angular velocity of the rotary valve.

The differential pressure and flow rate of the redirector inlet are

$$
\begin{aligned}
& \Delta P=P-P_{L S}, \\
& q_{1}=C_{d} A_{1}\left(x_{z}\right) \sqrt{\frac{2 \Delta P}{\rho}},
\end{aligned}
$$

where $C_{d}$ is the flow coefficient and $\rho$ is the fluid density.

According to previous research on and analysis of priority valves and redirectors [30], the differential pressure of the redirector orifice is basically a constant value. The flow rate through the inlet is relevant to the opening area of the rotary valve. In other words, it only depends on the rotation speed of the redirector control spool, not the electromotor speed or steering load.

The flow rate of the redirector through each damping hole can be expressed as

$$
q_{i}=C_{d} A_{i}\left(x_{z}\right) \sqrt{\frac{2 \Delta P_{i}}{\rho}},
$$

where $A_{i}$ is the area of the orifice, and $\Delta P_{i}$ is the pressure drop through each orifice.
When the redirector is in the medium position, medium damping holes $R_{2}$ and $R_{3}$ are working. Other damping holes are in a negative opening state, and $P_{L S}$ is low pressure.

$$
q_{z}=q_{2}=q_{3} .
$$

When the redirector rotates, $R_{2}$ and $R_{3}$ are closed. The flow rate of each damping hole is

$$
\begin{aligned}
& q_{z}=q_{7}=q_{1}+q_{6}=q_{9}=q_{L-R}+q_{8}, \\
& q_{m}=q_{1}=q_{4}=q_{5} .
\end{aligned}
$$

As Figure 4 shows, the differential pressure of oil through each damping hole is $\Delta P_{2}=\Delta P, \quad \Delta P_{3}=P_{L S}-P_{T}$, $\Delta P_{4}=P_{L S}-P_{H 1}, \Delta P_{5}=P_{H 2}-P_{F D}, \Delta P_{6}=P-P_{F D}, \Delta P_{7}=$ $P_{F D}-P_{L}, \Delta P_{L-R}=\Delta P_{8}=P_{L}-P_{R}$, and $\Delta P_{9}=P_{R}-P_{T}$.

The flow-rate-pressure relationship of the redirector can be transformed into

$$
\begin{aligned}
P= & \frac{\rho}{2}\left(\frac{q_{m}}{C_{d}}\right)^{2}\left(\frac{1}{\left(A_{4}\left(x_{z}\right)\right)^{2}}+\frac{1}{\left(A_{1}\left(x_{z}\right)\right)^{2}}+\frac{1}{\left(A_{5}\left(x_{z}\right)\right)^{2}}\right) \\
+ & \frac{T_{l}}{D_{m}}+\frac{\rho}{2}\left(\frac{q_{m}+q_{6}}{C_{d}}\right)^{2}\left(\frac{1}{\left(A_{7}\left(x_{z}\right)\right)^{2}}\right. \\
+ & \left.\frac{1}{\left(A_{9}\left(x_{z}\right)\right)^{2}}+\frac{1}{\left(A_{8}\left(x_{z}\right)+A_{z}\right)^{2}}\right)+P_{T}, \\
q_{6}^{2}= & \left(\left(\frac{A_{6}\left(x_{z}\right)}{A_{1}\left(x_{z}\right)}\right)^{2}+\left(\frac{A_{6}\left(x_{z}\right)}{A_{4}\left(x_{z}\right)}\right)^{2}+\left(\frac{A_{6}\left(x_{z}\right)}{A_{5}\left(x_{z}\right)}\right)^{2}\right) q_{m}^{2} \\
& +\frac{2 T_{l}}{\rho D_{m}}\left(C_{d}\right)^{2}\left(A_{6}\left(x_{z}\right)\right)^{2} .
\end{aligned}
$$

\section{Simulation Method and Related Settings}

\subsection{Simulation Method}

Research efficiency can be greatly improved by simulation verified by experiments [31]. Figure 2 shows that the circumferential movements of the redirector are converted into translational movements. A meter cylinder replaces the metering motor with an inlet and outlet instead of seven closed chambers to simplify the model structure. Only six inlet holes are considered during the translation in the same direction. In addition, the seven holes of the valve body corresponding to port $\mathrm{H}$ and the metering motor are equivalent to an inlet and a return port. The magnitude of the input force signal in the model represents the rotational speed of the steering wheel. The steering load is equivalent to the setting pressure of the two regulating valves.

Figure 5 shows the simulation model of the redirector. To improve the precision of the model, the physical 


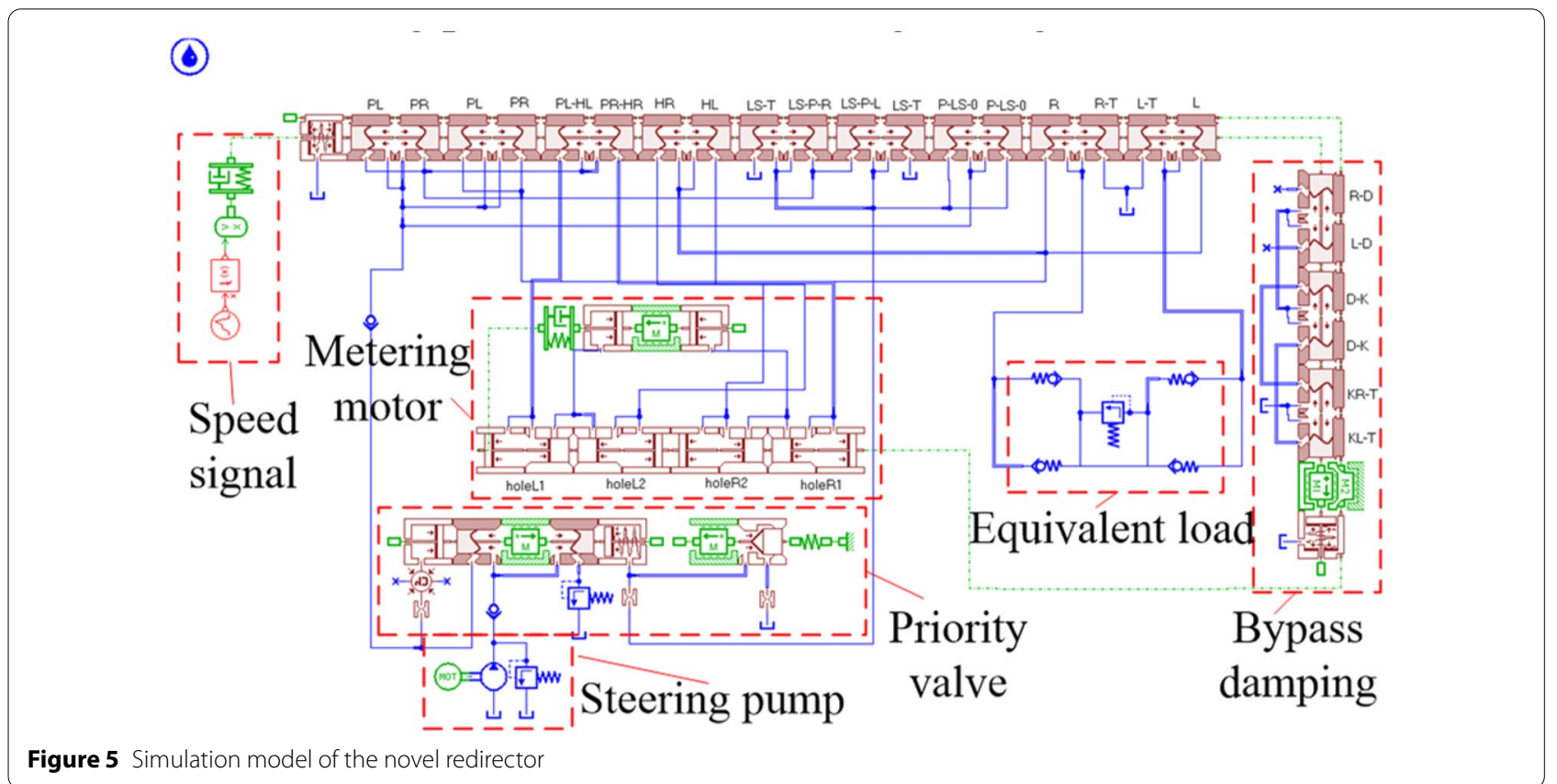

structures of the priority valve and redirector were split, and measurements were performed. The important parameters obtained are shown in Table 1. The hydraulic pressure acting on the control spool can be offset, so the acting area of the two relative valve blocks should be kept equal, and all parameters of the valve port area must be consistent. The initial position overlaps of the seven modules are calculated from the 2-D expansion diagram, and the specific parameter settings are listed in Table 1 . The opening area changes owing to the relative movement of the control spool, and the control sleeve is set according to Eqs. (1)-(9) in Section 3.1. The remaining unlisted parameters have the default values of the model.

A metering cylinder is used to replace the metering motor, and the displacement of the motor calculates the effective area of the cylinder.

$$
d=\frac{4 V}{\pi D^{2}} .
$$

If $n$ is the input signal of the steering wheel speed, the translation speed is defined as

$$
v=2 \pi r n .
$$

\subsection{Validation of the Model}

To verify whether the simulation model can accurately reflect the working principle and dynamic performance of an actual structure, the properties of a redirector with bypass damping under different working conditions were studied.
Table 1 Important parameters of the simulation model

\begin{tabular}{lll}
\hline Definition & Item & Value \\
\hline Priority valve & Spool diameter $(\mathrm{mm})$ & 25 \\
& Rod diameter $(\mathrm{mm})$ & 14 \\
& Mass $(\mathrm{kg})$ & 0.3 \\
& Preload $(\mathrm{N})$ & 458.8 \\
& Stiffness $(\mathrm{N} / \mathrm{mm})$ & 28.3 \\
Pump & Displacement $(\mathrm{L} / \mathrm{rev})$ & 0.08 \\
Signal & Input & $0.001675 x$ \\
Redirector & Spool diameter $(\mathrm{mm})$ & 10 \\
& Rod diameter(mm) & 5 \\
& Mass 1 $(\mathrm{kg})$ & 0.284 \\
& Mass 2 $(\mathrm{kg})$ & 0.301 \\
Metering motor & Mass 0 $(\mathrm{kg})$ & 0.6 \\
& Piston diameter (mm) & 79.6 \\
Fluid & Density $\left(\mathrm{kg} / \mathrm{m}^{3}\right)$ & 850 \\
Working module H-R/L & Underlap corresponding & -0.58 \\
Return module R/L-T & to zero displacement & -0.72 \\
Bypass module R/L-D & (mm) & -0.545 \\
Inlet module P-C & & -0.89 \\
Module H & & -0.33 \\
Load sensor module LS & & 0.38 \\
Bypass module D-K & & -0.545 \\
Flow rate amplification module & & -1.22 \\
A-C & & \\
\hline
\end{tabular}

Figure 6 shows the displacement curve of the control spool and control sleeve under a certain rotating speed signal. The curves illustrate that the control spool begins 


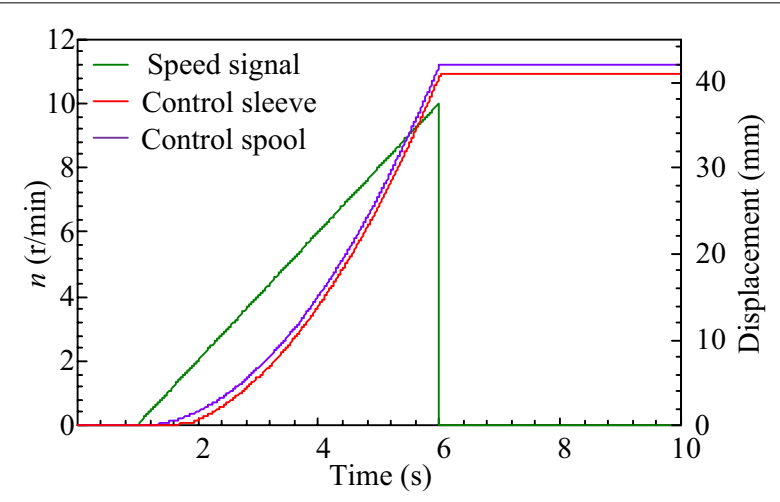

Figure 6 Displacement of control spool and sleeve

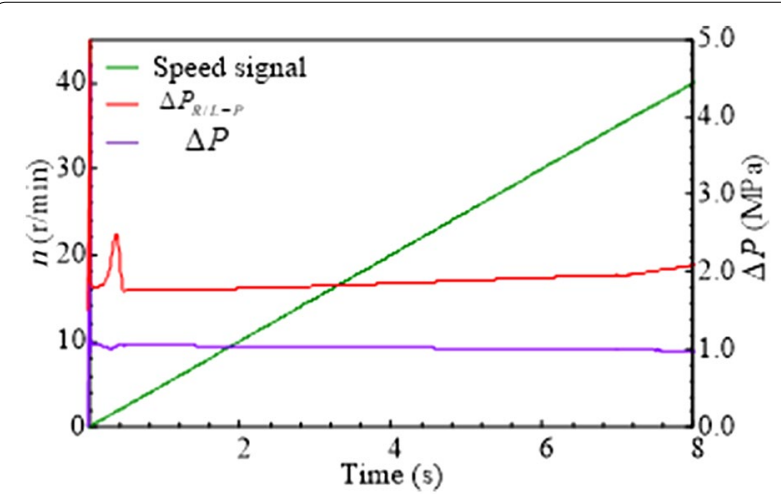

Figure 7 Relation between speed signal and $\Delta P, \Delta P_{R / L-P}$

to move immediately when the force signal is applied, whereas the control sleeve does not move because of the dead zone between the control spool and control sleeve. The opening area and displacement gap between the control spool and control sleeve expand with increasing rotation speed and opening port $\mathrm{P}$. When the rotation speed is 0 , the opening area is reduced to 0 , and the control sleeve has a slight lag in the stop movement relative to the control spool. The simulation results show that the control spool and control sleeve of the redirector ensure good follow-up performance when the steering wheel speed increases.

Figure 7 shows the differential pressure $\Delta P$ and pressure loss $\Delta P_{R / L-P}$ of the redirector under a constant increasing speed signal. It is clear that $\Delta P_{R / L-P}$ gradually increases with the increase in the redirector opening area, whereas $\Delta P$ remains constant. The overflow area and flow rate of the redirector both increase while turning the steering wheel quickly. However, $\Delta P_{R / L-P}$ increases as the overflow area increases because the overflow area gradient of each orifice is smaller than that of the flow rate.
Based on the simulation results, the model completely represents the actual structure of the redirector, which reflects the working principle well and obtains good following characteristics.

\subsection{Simulation Results}

The dynamic characteristics of the redirector with bypass damping are analyzed for different steering wheel speeds, different electromotor speeds, and different steering loads.

Figure 8 shows the simulation results of the redirector under different steering wheel speeds with a speed of 708 $\mathrm{r} / \mathrm{min}$ under a no load condition. The simulation curves reveal that the flow rate of the redirector increases with an increase in the steering wheel speed. The flow rate has a linear relationship with the opening area $A_{1}$ when $\Delta P$ remains stable, and the redirector has good operating performance. The flow amplification holes are opened at rotation speeds of 20 and $30 \mathrm{r} / \mathrm{min}$, and the flow rate increases rapidly. In addition, this part of the flow rate directly reaches the outlet of the redirector without passing through the metering motor.

Figure 9 displays the simulation results of the redirector under different electromotor speeds with a no load condition and a steering wheel speed of $20 \mathrm{r} / \mathrm{min}$. When the electromotor speed changes, the flow rate into the redirector and the pressure of ports $\mathrm{P}, \mathrm{LS}$, and $\mathrm{L} / \mathrm{R}$ remain constant. This is because the flow rate required by the steering system is constant and is not affected by the electromotor speed when the steering wheel speed is fixed.

Figure 10 shows the simulation results under no load and heavy load conditions with the steering wheel speed and electromotor speed fixed. The output pressure and pressure shock of the redirector under a heavy load are higher than under no load, but the oil return pressure in both cases is the same. According to an analysis of the simulation results, the change of load has no effect on the flow rate and differential pressure of the redirector with the same steering speed.

Figure 10 shows that with the input of the step signal, the rise time under no load is $0.23 \mathrm{~s}$, which is shorter than $0.49 \mathrm{~s}$ under a heavy load. The steering system response slows when the load becomes heavy.

\section{Redirector Experiment}

\subsection{Experiment Simulation Platform}

Although the simulation model was set according to the actual structural parameters, the influence of the pipeline was ignored. Therefore, it was necessary to verify the correctness of the equivalent load and model experimentally. According to the simulation system model in Figure 5, the experiment simulation platform of the bypass damping redirector was established, as shown in 

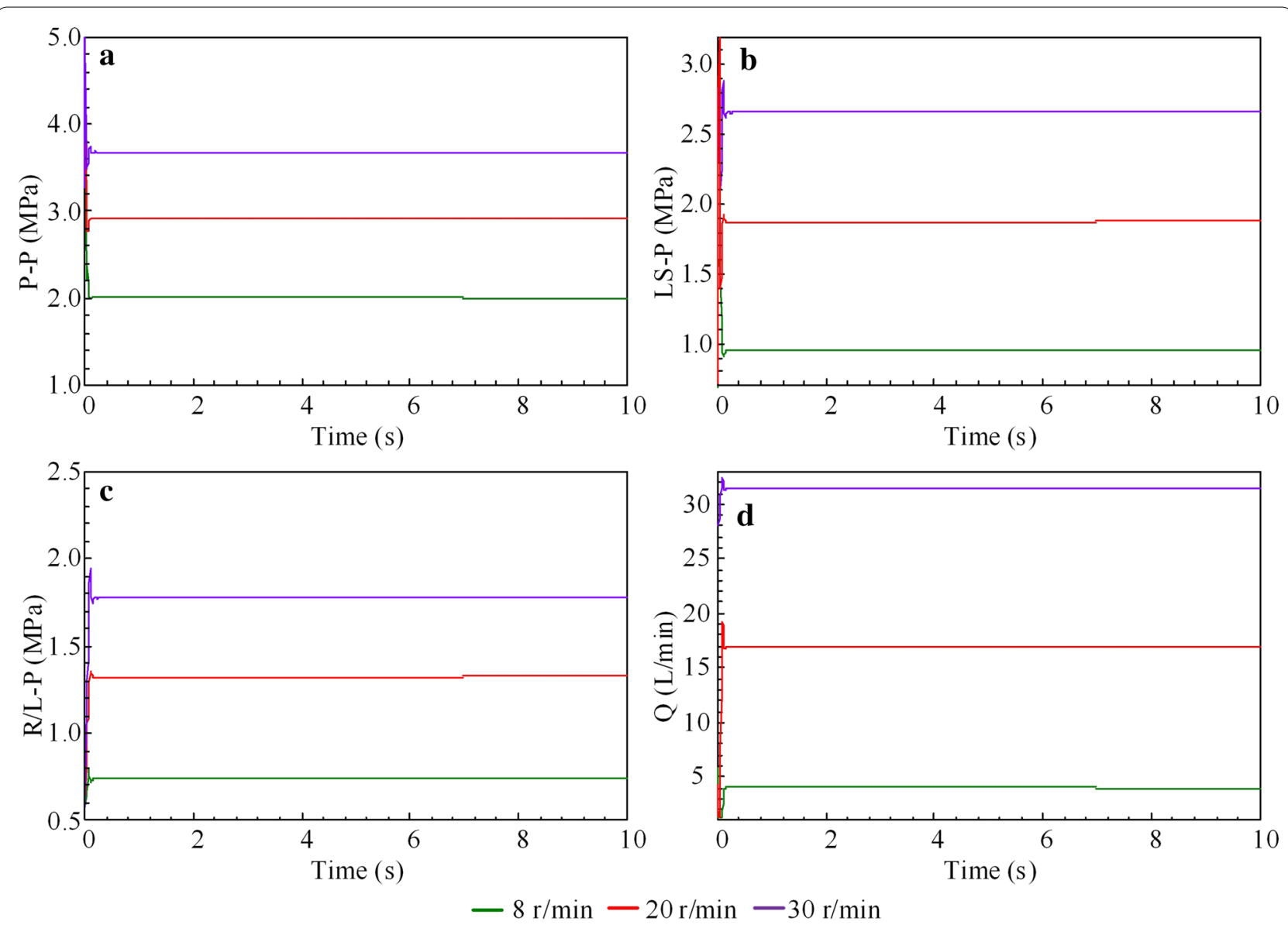

Figure 8 Simulation results under no load condition and electromotor speed of $708 \mathrm{r} / \mathrm{min}: \mathbf{a} P, \mathbf{b} P_{L S}, \mathbf{c} P_{R / L}$, and $\mathbf{d} Q$

Figure 11. The experiment simulation platform mainly consisted of a priority valve, redirector, and equivalent load to form a load-sensing steering system. The main function of the priority valve was to ensure that the fluid in the main circuit was preferentially supplied to the steering system, and the excess fluid was unloaded through port $\mathrm{EF}$ of the priority valve.

When the platform is assembled, the bending degree of the pipelines should be reduced as much as possible to reduce the influence of pressure loss on the measured data. Sensors should be installed as close as possible to the pressure point. In the experiment, the angular velocity of the steering wheel was measured using a speed measuring instrument. Figure 11 shows the relevant data acquisition and measurement devices used during the experiments. The output pressure of the hydraulic pump was measured using pressure sensors with a range of 0-60 MPa. The pressures of the redirector inlet, outlet, and port LS were measured by pressure sensors with a range of 0-40 $\mathrm{MPa}$. The accuracy of the pressure sensor was $0.1 \%$. Flow meters were used to collect the flow rates of the redirector inlet and outlet. The sensed data were transmitted to the HMG 3000 data acquisition device with a sampling frequency of $200 \mathrm{~Hz}$, and then a computer was used to store, display, and play back the collected data. The detailed parameters of the experimental instruments are given in Table 2.

\subsection{Experimental Results}

The performance of the redirector with bypass damping was tested and analyzed under three steering conditions with different steering wheel speeds, different electromotor speeds, and different steering loads. The steering conditions in the experiment were consistent with the simulation steering condition to ensure the accuracy of the experimental results.

Figure 12 shows the experimental results of the redirector with bypass damping under no load with an electromotor speed of $708 \mathrm{r} / \mathrm{min}$ when the steering wheel speeds are 8,20 , and $30 \mathrm{r} / \mathrm{min}$. There is a significant positive correlation between the steering wheel speed and flow rate through the redirector, which leads to an 

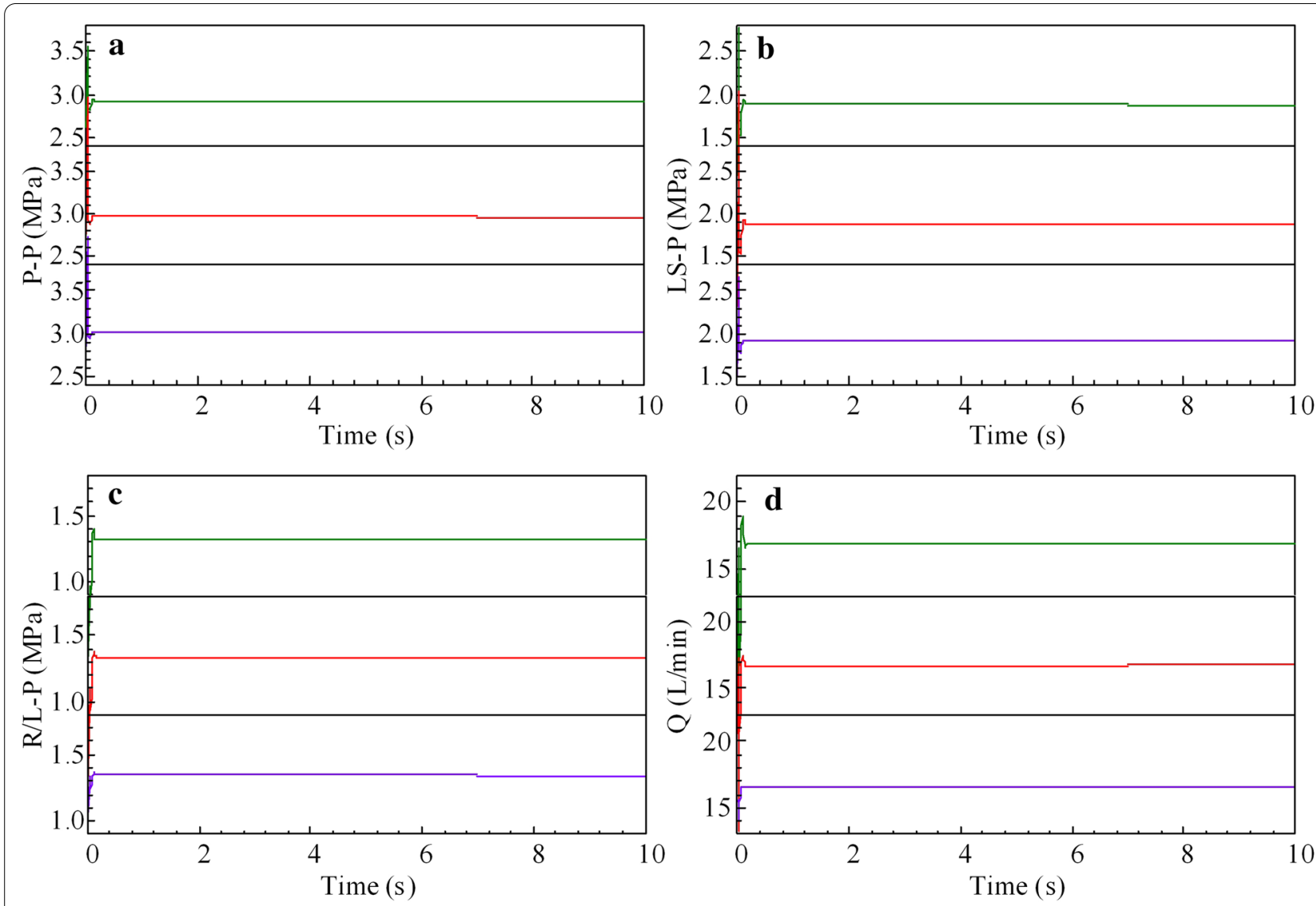

$-708 \mathrm{r} / \mathrm{min}-1200 \mathrm{r} / \mathrm{min}-1870 \mathrm{r} / \mathrm{min}$

Figure 9 Simulation results under no load condition and steering wheel speed of $20 \mathrm{r} / \mathrm{min}: \mathbf{a} P, \mathbf{b} P_{L S}, \mathbf{c} P_{R / L}$, and $\mathbf{d} Q$

increase in the pressure fluctuation of ports LS and L/R. The steering wheel speed is the main factor that affects the flow rate of the steering system. At a high steering speed, the inlet flow rate of the redirector improves dramatically with an increase in steering wheel speed.

Figure 13 shows the experimental results under no load with a steering wheel speed of $20 \mathrm{r} / \mathrm{min}$ when the electromotor speeds are 708, 1200, and $1870 \mathrm{r} / \mathrm{min}$. When the electromotor speed increases, the flow rate through the redirector and the pressure at ports $\mathrm{P}, \mathrm{LS}$, and $\mathrm{R} / \mathrm{L}$ remain constant. Therefore, the required flow rate of the steering system is determined by the steering wheel speed rather than the electromotor speed.

Figure 14 shows the experimental results under no load and heavy load with a steering speed of $8 \mathrm{r} / \mathrm{min}$ and electromotor speeds of 708 and $1200 \mathrm{r} / \mathrm{min}$. The pressure at ports $\mathrm{P}, \mathrm{LS}$, and R/L builds up significantly with the increase in steering load, whereas the pressure variation of port $\mathrm{R}$ is not obvious. The results, combined with the previous simulation analysis, show that the pressure of the steering system increases and the response slows down when the steering load increases.
Table 3 shows a comparison between the simulation and experimental results of the flow rate and pressure of each port of the redirector under different working conditions. The main reason for the difference between them is that the friction of the redirector model and the metering motor resistance in the simulation are estimated values that differ from the real values. The maximum error between the simulation and experimental results is $11.1 \%$, proving that the simulation model is accurate. The model demonstrates that further research on steering performance is justified.

\section{Analysis of Dynamic Characteristics and Oscillation}

According to the force equation and flow continuity equation of the redirector and steering load during the steering process,

$$
A_{L} P_{L}-A_{R} P_{R}=m \frac{\mathrm{d} u}{\mathrm{~d} t}+B u(t)+F(t)
$$



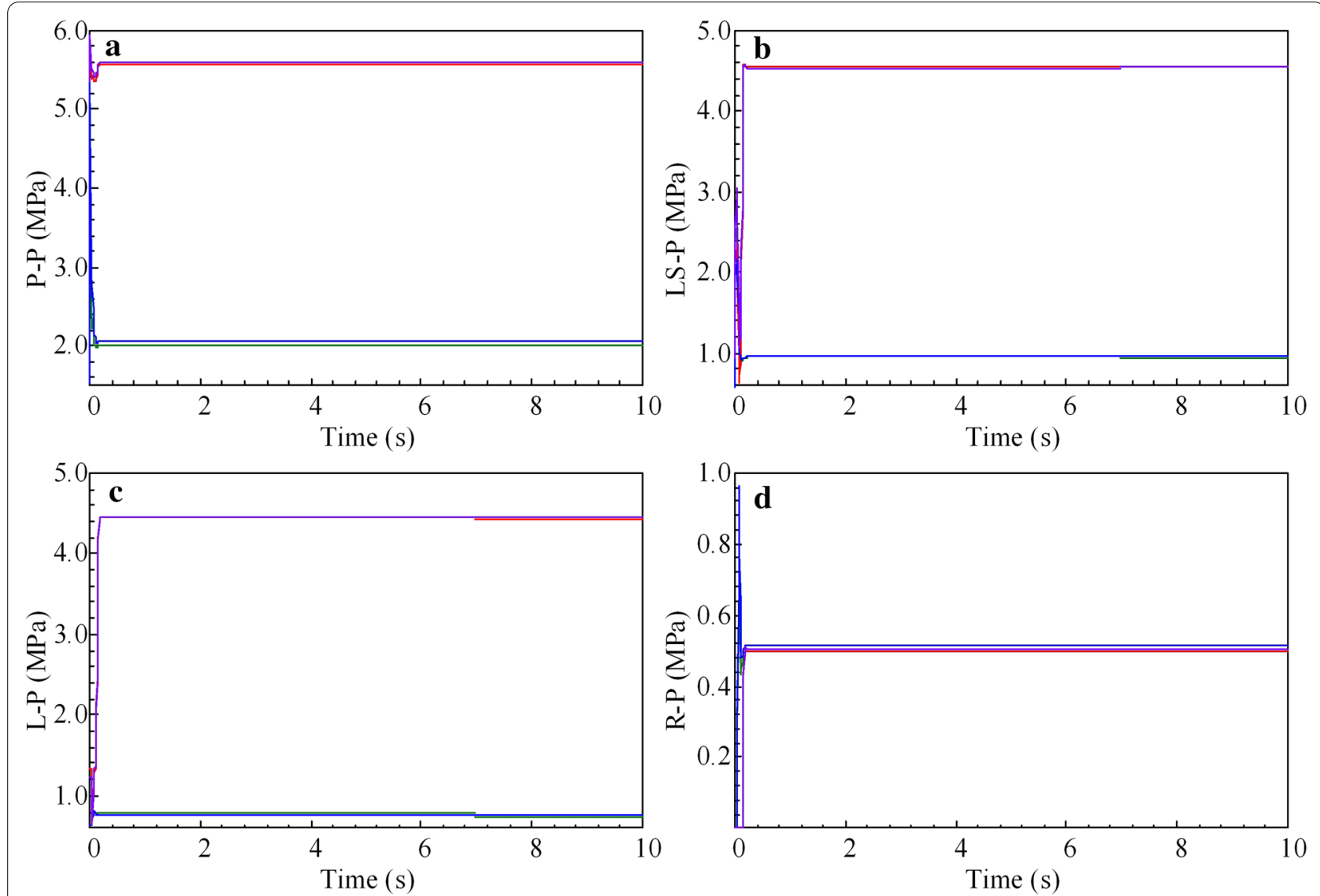

No load $-708 \mathrm{r} / \mathrm{min}-1200 \mathrm{r} / \mathrm{min}$ Heavy load $-708 \mathrm{r} / \mathrm{min}-1200 \mathrm{r} / \mathrm{min}$

Figure 10 Simulation results under steering wheel speed of $8 \mathrm{r} / \mathrm{min}$ and electromotor speed of $708 \mathrm{r} / \mathrm{min}: \mathbf{a} P, \mathbf{b} P_{L S}, \mathbf{c} P_{L}$, and $\mathbf{d} P_{R}$

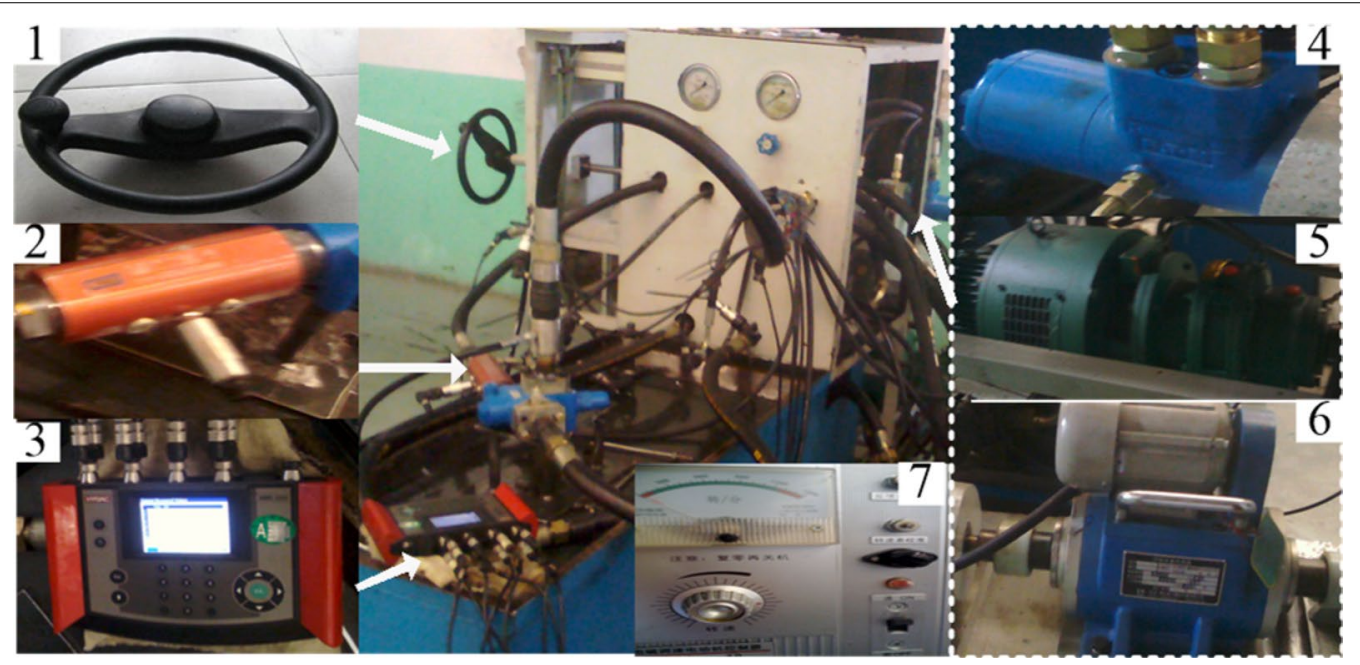

Figure 11 Photograph of the redirector experimental platform: (1) steering wheel, (2) pressure sensor, (3) data acquisition, (4) redirector, (5) pump, (6) electromotor, and (7) controller 
Table 2 Main parameters and size of the experimental platform

\begin{tabular}{ll}
\hline Definition & Parameters \\
\hline Pump & Displacement: $80 \mathrm{cc} / \mathrm{rev}$ \\
& Max. rotation speed: $2350 \mathrm{r} / \mathrm{min}$ \\
Data acquisition & Signal: $1-5 \mathrm{~V}$, Accuracy: 0.02\%, Channels: 8 \\
Pressure sensor & Range: 0-60/40 MPa, Accuracy: 0.1\%, Voltage: 12 VDC \\
Flow meter & Range: $300 \mathrm{~L} / \mathrm{min}$, Accuracy: $1 \%$ \\
Tachometer & Range: 0-3000 r/min, Accuracy: 1\%
\end{tabular}

$$
q_{L-R}(t)=A_{L} u(t)+\frac{V}{E} \frac{\mathrm{d} P_{L}(t)}{\mathrm{d} t}+\lambda_{c}\left[P_{L}(t)-P_{R}(t)\right]
$$

where $V$ is the chamber volume of the equivalent load, $E$ is the effective bulk modulus of oil, $F$ is the external load, $u(t)$ is the speed of the equivalent load response, $B$ is the viscous damping, and $\lambda_{c}$ is the leakage coefficient of the equivalent load.
The redirector with bypass damping has the following pressure-flow-rate linearization equation of the steering load.

$$
q_{8}=q_{7}-q_{L-R}=K_{q} A_{8}(s)+K_{c}\left(P_{L}-P_{R}\right),
$$

where $K_{q}=\frac{\partial q_{8}}{\partial x}=C_{d} \sqrt{2 \frac{P_{L}-P_{R}}{\rho}}, K_{\mathrm{c}}=\frac{\partial q_{8}}{\partial P_{L}}=\frac{C_{d} A_{8}}{\sqrt{2 \rho\left(P_{L}-P_{R}\right)}}$.

A block diagram of the dynamic characteristics of the two redirector structures is obtained by Laplace transformation, as shown in Figure 15. The variables inside the dotted line represent the influence of the bypass damping structure.

When the right outlet pressure $P_{R}(s)=0$ and flow rate $q_{7}(\mathrm{~s})=0$, the dynamic transfer function with a load input and left outlet pressure output can be denoted as

$$
\frac{P_{L}(s)}{F(s)}=\frac{\frac{A_{L} E}{m V}}{s^{2}+\left(\frac{\lambda_{c} E}{V}+\frac{B}{m}\right) s+\frac{B \lambda_{c}+A_{L}^{2}}{m V} E}=\frac{K_{A 1} \omega_{n 1}^{2}}{s^{2}+2 \xi_{1} \omega_{n 1} s+\omega_{n 1}^{2}} .
$$
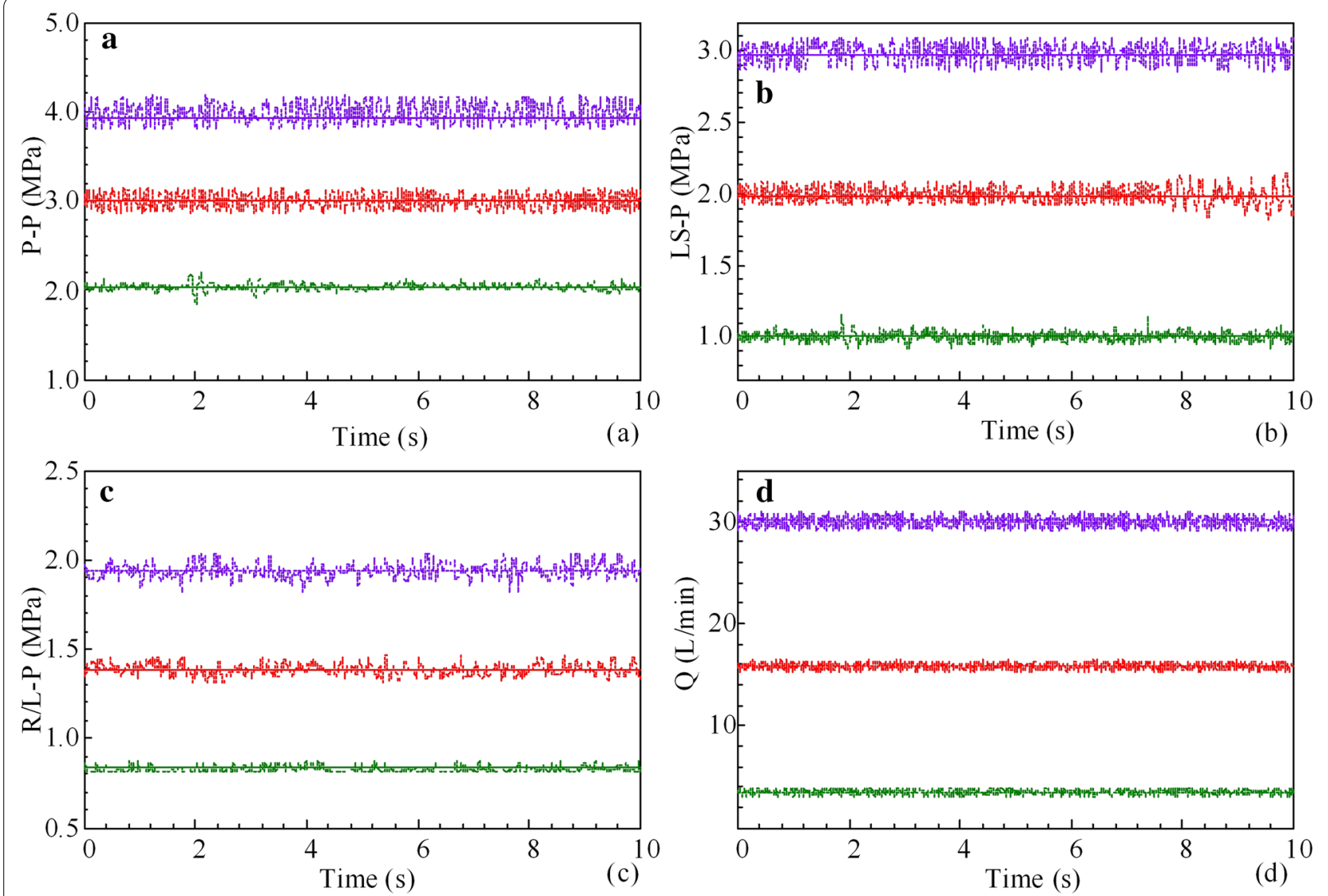

$-8 \mathrm{r} / \mathrm{min}-20 \mathrm{r} / \mathrm{min}-30 \mathrm{r} / \mathrm{min}$

Figure 12 Experimental results under no load condition and electromotor speed of $708 \mathrm{r} / \mathrm{min}: \mathbf{a} P, \mathbf{b} P_{L S}, \mathbf{c} P_{R / L}$, and $\mathbf{d} Q$ 

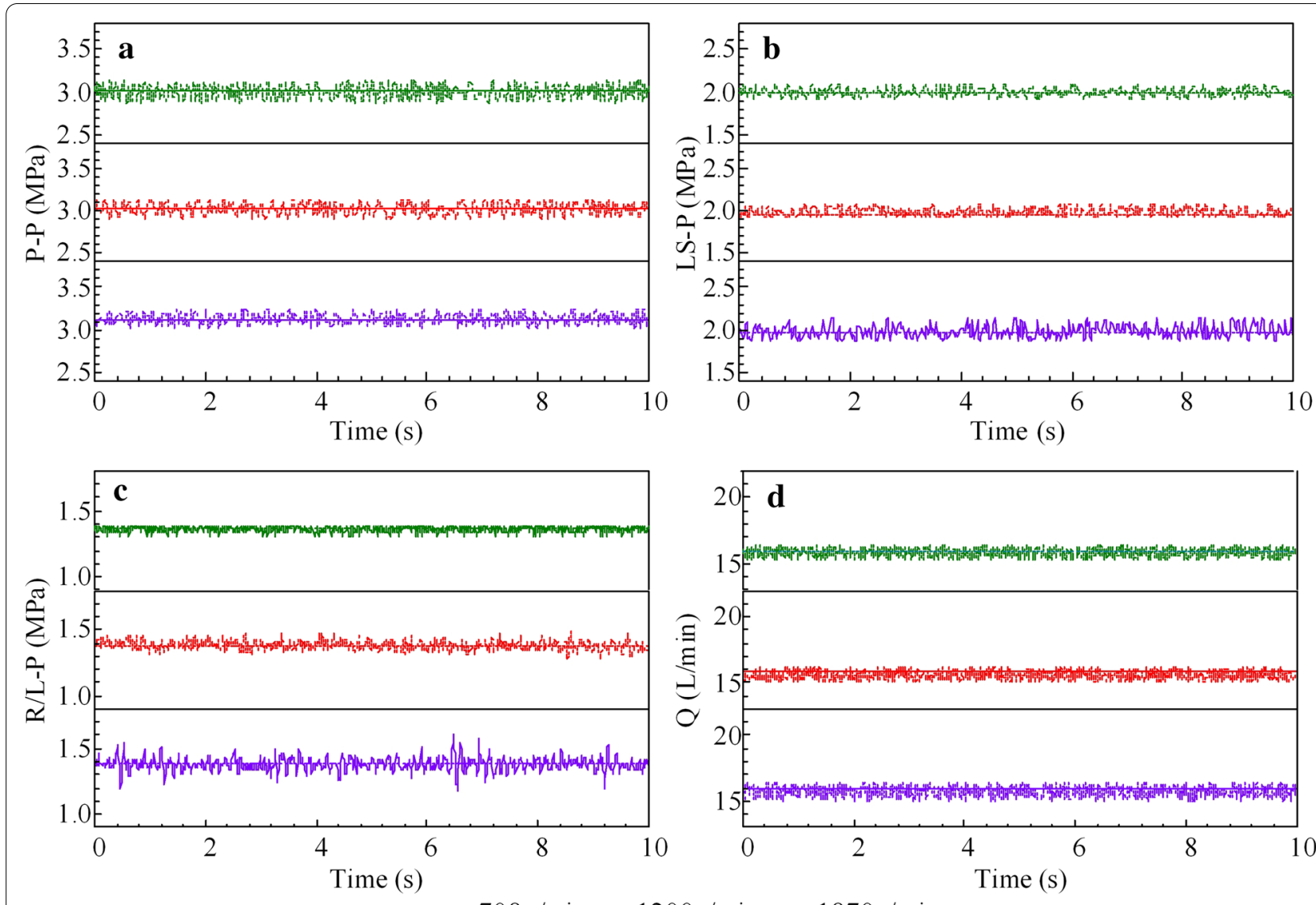

Figure 13 Experimental results under no load condition and steering wheel speed of $20 \mathrm{r} / \mathrm{min}: \mathbf{a} P, \mathbf{b} P_{L S}, \mathbf{c} P_{R / L}$, and $\mathbf{d} Q$

Combining Eqs. (23)-(25), the dynamic transfer function of the redirector with bypass damping is

$$
\begin{gathered}
\frac{P_{L}(s)}{F(s)}=\frac{\frac{A_{L} E}{m V}}{s^{2}+\left(\frac{E\left(\lambda_{c}+K_{c}\right)}{V}+\frac{B}{m}\right) s+\frac{\left(\lambda_{c}+K_{c}\right) B+A_{L}^{2}}{m V} E}, \\
=\frac{K_{A 2} \omega_{n 2}^{2}}{s^{2}+2 \xi_{2} \omega_{n 2} s+\omega_{n 2}^{2}} .
\end{gathered}
$$

The gains of the two structure redirectors are

$$
\begin{aligned}
K_{A 1} & =\frac{A_{L}}{B \lambda_{c}+A_{L}^{2}}, \\
K_{A 2} & =\frac{A_{L}}{\left(\lambda_{c}+K_{c}\right) B+A_{L}^{2}} .
\end{aligned}
$$

The undamped natural frequencies are

$$
\begin{aligned}
\omega_{n 1} & =\sqrt{\frac{E}{m V}\left(B \lambda_{c}+A_{L}^{2}\right),} \\
\omega_{n 2} & =\sqrt{\frac{E}{m V}\left(B \lambda_{c}+B K_{c}+A_{L}^{2}\right)} .
\end{aligned}
$$

The system damping ratios are

$$
\begin{aligned}
& \xi_{1}=\frac{\omega_{n 1}}{2 A_{L}^{2}}\left(m \lambda_{c}+\frac{B V}{E}\right), \\
& \xi_{2}=\frac{\omega_{n 2}}{2 A_{L}^{2}}\left(m \lambda_{c}+m K_{c}+\frac{B V}{E}\right) .
\end{aligned}
$$

The outlet characteristic equations of the two structure redirectors are 

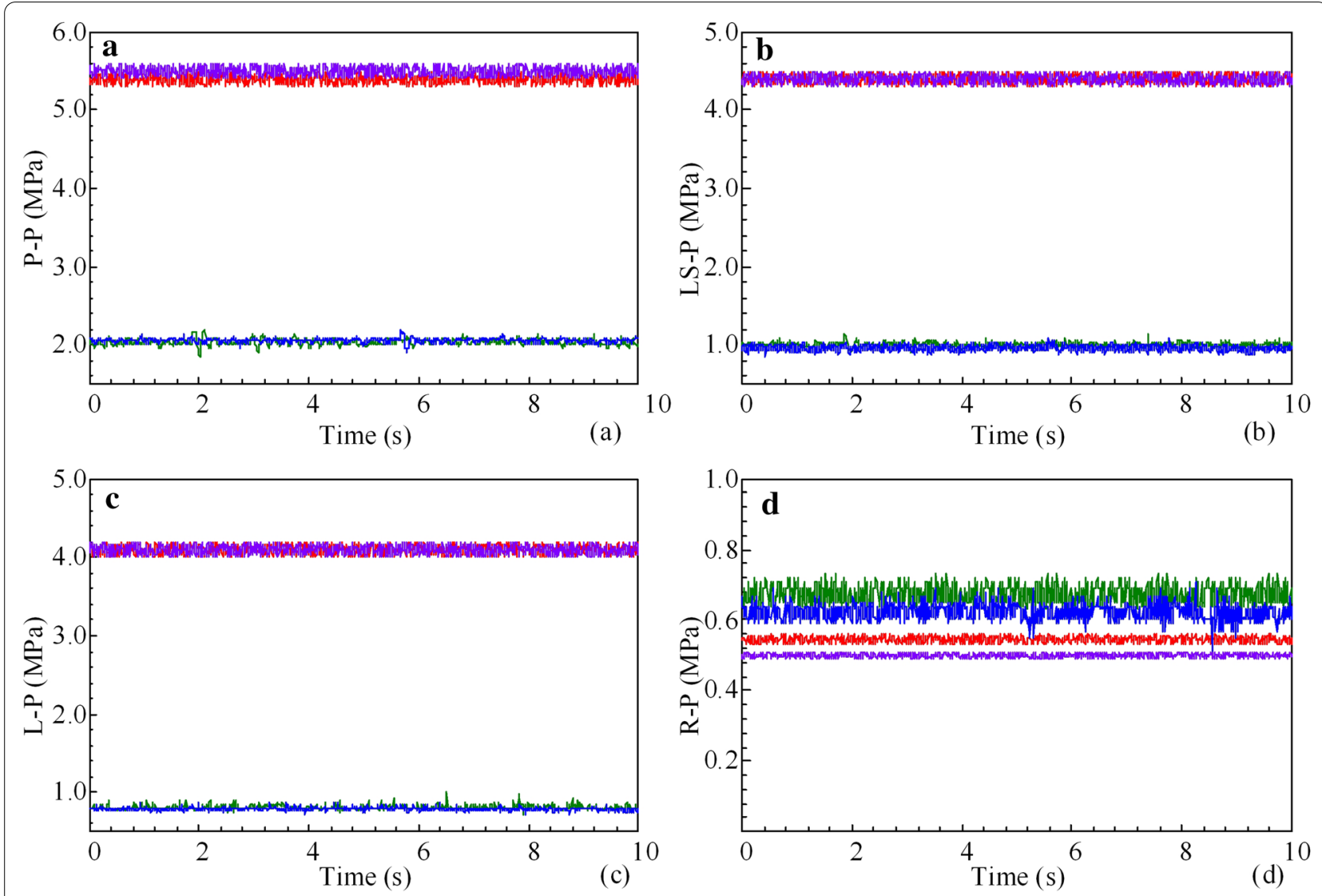

No load $-708 \mathrm{r} / \mathrm{min}-1200 \mathrm{r} / \mathrm{min}$ Heavy load $-708 \mathrm{r} / \mathrm{min}-1200 \mathrm{r} / \mathrm{min}$

Figure 14 Experimental results under steering wheel speed of $8 \mathrm{r} / \mathrm{min}$ and electromotor speed of $708 \mathrm{r} / \mathrm{min}: \mathbf{a} P, \mathbf{b} P_{L S}, \mathbf{c} P_{L}$, and $\mathbf{d} P_{R}$

Table 3 Part of the simulation and experimental results

\begin{tabular}{|c|c|c|c|c|c|}
\hline $\begin{array}{l}\text { Working } \\
\text { condition }\end{array}$ & Category & $P(\mathrm{MPa})$ & $P_{L S}(\mathrm{MPa})$ & $P_{R / L}(\mathrm{MPa})$ & $Q(\mathrm{~L} / \mathrm{min})$ \\
\hline \multirow{3}{*}{$\begin{array}{l}708 \mathrm{r} / \mathrm{min} \\
8 \mathrm{r} / \mathrm{min} \\
\text { No load }\end{array}$} & Simulation & 2.01 & 0.95 & 0.75 & 4 \\
\hline & Experiment & 2.04 & 1.00 & 0.83 & 3.6 \\
\hline & Error (\%) & 1.6 & 4.9 & 10.6 & 11.1 \\
\hline \multirow{3}{*}{$\begin{array}{l}708 \mathrm{r} / \mathrm{min} \\
30 \mathrm{r} / \mathrm{min} \\
\text { No load }\end{array}$} & Simulation & 3.68 & 2.66 & 1.78 & 31.53 \\
\hline & Experiment & 3.94 & 2.97 & 1.93 & 30.22 \\
\hline & Error (\%) & 6.5 & 10.4 & 8.2 & 4.3 \\
\hline \multirow{3}{*}{$\begin{array}{l}1200 \mathrm{r} / \mathrm{min} \\
20 \mathrm{r} / \mathrm{min} \\
\text { No load }\end{array}$} & Simulation & 2.96 & 1.89 & 1.33 & 16.91 \\
\hline & Experiment & 3.02 & 1.95 & 1.36 & 15.86 \\
\hline & Error (\%) & 1.8 & 2.9 & 0.5 & 6.6 \\
\hline $1870 \mathrm{r} / \mathrm{min}$ & Simulation & 3.02 & 1.91 & 1.34 & 16.56 \\
\hline $20 \mathrm{r} / \mathrm{min}$ & Experiment & 3.12 & 1.97 & 1.38 & 15.97 \\
\hline No load & Error (\%) & 3.2 & 3.2 & 2.6 & 3.7 \\
\hline
\end{tabular}

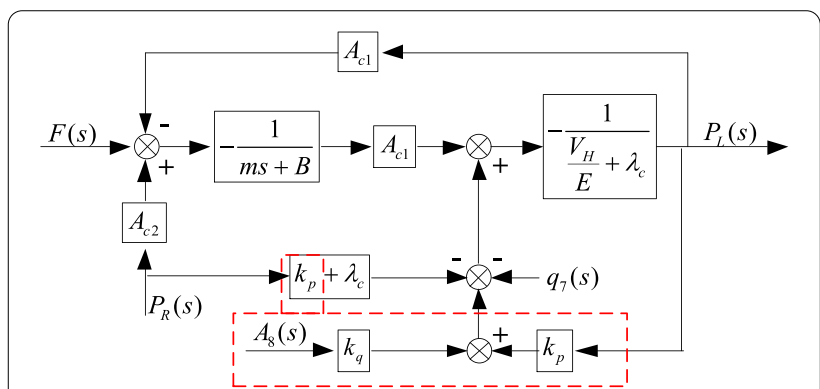

Figure 15 Schematic of redirector mathematical model

$$
s^{2}+\left(\frac{\lambda_{c} E}{V}+\frac{B}{m}\right) s+\frac{E}{m V}\left(B \lambda_{c}+A_{L}^{2}\right)=0
$$




$$
s^{2}+\left(\frac{\left(\lambda_{c}+K_{c}\right) E}{V}+\frac{B}{m}\right) s+\frac{E}{m V}\left(B \lambda_{c}+B K_{c}+A_{L}^{2}\right)=0 .
$$

The pressure overshoot is

$$
M_{p n}=\exp \left(-\frac{\xi_{n} \pi}{\sqrt{1-\xi_{n}^{2}}}\right) .
$$

According to the Routh-Hurwitz stability criterion, both systems formed by the two redirectors are stable.

Based on the above equations, when the steering load $F$ increases, the load pressure $P_{L}$ increases, the throttle pressure-flow coefficient $K_{c}$ decreases, the undamped natural frequency $\omega_{n}$ and the system damping ratio $\xi$ decrease, and the pressure overshoot $M_{P}$ increases. The number of system oscillations increases, stability decreases, and adjustment time increases. Therefore, a sudden increase in the steering load leads to system oscillation. If the opening area $A_{8}$ of the orifice $R_{8}$ increases, $K_{c}$ increases, $\xi$ increases, and the pressure overshoot $M_{P}$ decreases. The number of oscillations decreases, and the corresponding stability of the system increases. In this study, $\xi_{1}<\xi_{2}, M_{P 1}>M_{P 2}$, and the overshoot of the redirector with bypass damping is relatively small.

The severity of the system oscillation is determined by the damping ratio $\xi$. The smaller $\xi$ is, the more severe the oscillation. The decay speed of the oscillation process is determined by $\left|\xi \omega_{n}\right|$. The larger $\left|\xi \omega_{n}\right|$ is, the faster the decay. According to the above analysis,

$$
\left|\xi \omega_{n}\right|_{1}<\left|\xi \omega_{n}\right|_{2}
$$

Therefore, compared with the traditional redirector, the output pressure oscillation decays more quickly, and the system is more stable when a step signal is added to the redirector with bypass damping.

Figure 16 shows the flow rate curve through the bypass loop under different steering wheel speeds under no load with an electromotor speed of $708 \mathrm{r} / \mathrm{min}$. The bypass

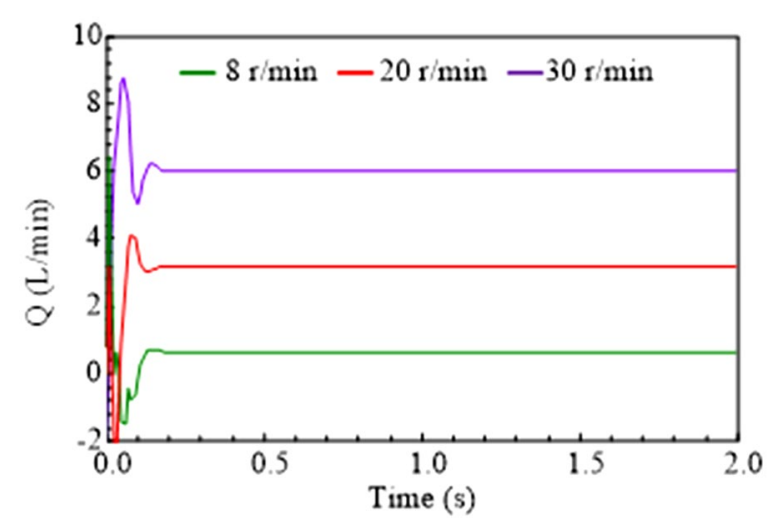

Figure $\mathbf{1 6}$ Flow rate through bypass orifices loop flow rates are $0.66,3.15$, and $6.03 \mathrm{~L} / \mathrm{min}$ when the steering wheel speeds are 8,20 , and $30 \mathrm{r} / \mathrm{min}$, respectively, accounting for $16.5 \%, 18.6 \%$, and $19.1 \%$ of the total flow rate into the redirector, respectively. The simulation results prove that the flow rate through the bypass loop increases with the increase in steering wheel speed, but the increase rate decreases. The proportion of flow rate through the bypass loop is relatively stable.

Figure 17 shows the equivalent load inlet pressure simulation curves of the two redirectors under no load and heavy load with an electromotor speed of $708 \mathrm{r} /$ min. Under no load and a steering wheel speed of $20 \mathrm{r} /$ min, the equivalent load inlet pressure overshoot of the redirector with bypass damping reduces from 0.86 to $0.79 \mathrm{MPa}$ compared with the original redirector. Under a heavy load, the pressure overshoot reduces from 6.50 to $5.64 \mathrm{MPa}$, with a decrease rate of $13.4 \%$. The pressure oscillation duration is reduced from 2.09 to $1.6 \mathrm{~s}$, with a decrease rate of $23.4 \%$. The research presented in this article can contribute to the stability optimization of articulated vehicle steering technology.

\section{Conclusions}

To reduce the pressure oscillation and enhance the stability of an articulated vehicle steering system, a novel redirector with bypass damping was proposed. The steering load was equivalently replaced to make the research conditions more convenient to control. Simulation, experimental research, and analysis of the novel redirector under different working conditions were conducted. The main conclusions of this work are as follows.

(1) For the redirector with bypass damping, the peak value of the equivalent load inlet pressure is reduced from 6.50 to $5.64 \mathrm{MPa}$ under a heavy load condition during steering. Compared with the traditional redirector, the overshoot is reduced by

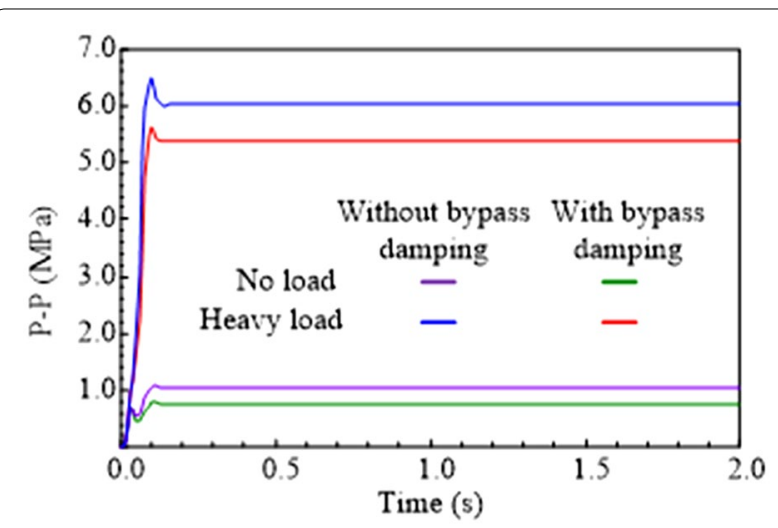

Figure 17 Pressure of the equivalent load inlet 
$13.4 \%$, decreasing the number of system oscillations.

(2) The output pressure oscillation duration caused by the load change of the redirector with bypass damping is reduced by $23.4 \%$ compared with the traditional redirector. The pressure oscillation decays faster, and the system is more stable.

(3) For the redirector with bypass damping, the flow rate through the bypass loop increases with the increase in steering wheel speed, but the rate of increase decreases. The proportion of flow rate through the bypass loop is relatively stable. Therefore, the bypass damping structure has little effect on the flow rate supply during steering.

Although the redirector with bypass damping improves steering system stability, it has a negative impact on steering sensitivity, which increases the steering response time to a certain extent and causes steering lag. In future research, it is necessary to coordinate the contradiction between the stability and sensitivity of the bypass damping structure to achieve the optimal relationship. The experimental simulation platform used in this study could not fully reflect the change in the steering load. In subsequent research, the novel redirector should be applied to a performance test of a prototype vehicle to improve the accuracy of the experimental test further.

\section{Acknowledgements}

Not applicable.

\section{Authors' Contributions}

$\mathrm{XL}$, JC conceived the idea of the study; YW, DH performed the theoretical derivation and simulation experiment. JC contributed to structure design. YW analyzed the data and wrote the manuscript. All authors read and approved the final manuscript.

\section{Authors' Information \\ Yuqi Wang, born in 1993, is currently a PhD candidate at School of Mechani- cal and Aerospace Engineering, Jilin University, China. She received bachelor's degree from Jilin University, China, in 2016. Her research interests include fluid power transmission and control. \\ Xinhui Liu, born in 1962, is currently a professor at School of Mechanical and Aerospace Engineering, Jilin University, China. \\ Jinshi Chen, born in 1983, is currently an associate professor at School of Mechanical and Aerospace Engineering, Jilin University, China. \\ Dongyang Huo, born in 1996, is currently a master candidate at School of Mechanical and Aerospace Engineering, Jilin University, China.}

\section{Funding}

Supported by National Key Research and Development Program of China (Grant No. 2018YFB2000900).

\section{Competing interests}

The authors declare no competing financial interests.

Received: 11 June 2020 Revised: 23 August 2021 Accepted: 18 October 2021

Published online: 12 November 2021

\section{References}

[1] X Yan, J Yang, L Quan. Co-simulation and experiment of wheel loader during operation process. Transactions of the Chinese Society of Agricultural Engineering, 2015, 31(16): 102-109.

[2] X Wang, J Yang, L Quan, et al. A novel high-efficiency wheel loader power steering system with fault-tolerant capability. IEEE Transactions on Vehicular Technology, 2018, 67(10): 9273-9283.

[3] Z Meng, $\mathrm{H}$ Zang. Analysis of hydraulic steering system of tracked all-terrain vehicles' articulated mechanism. AlP Conference Proceedings, 2018, 1955(1): 030003-1-030003-7.

[4] TXu, Y Shen, Y Huang, et al. Study of hydraulic steering process for articulated heavy vehicles based on the principle of the least resistance. IEEE/ASME Transactions on Mechatronics, 2019, 24(4): 1662-1673.

[5] Zardin B, Borghi M, Gherardini F, et al. Modelling and simulation of a hydrostatic steering system for agricultural tractors. Energies, 2018, 11(1): 230.

[6] D Lei, K Deng, YP Gong. The optimum design for pivot points of steering mechanism on HT25J wheel loader. 2011 International Conference on Consumer Electronics, Communications and Networks (CECNet), Xianning, China, April 16-28, 2011: 2760-2763.

[7] T J Wang, J S Chen, F Zhao, et al. Combined simulation and test of hydraulic steering system. Journal of Jilin University (Engineering Science Edition), 2013, 43(3): 607-612. (in Chinese)

[8] CWang, Y Zhang, W Zhao. Multi-objective optimization of a steering system considering steering modality. Advances in Engineering Software, 2018, 126: 61-74.

[9] K Kitahara, K Kazama, H Mouri. Design of a new steering system to solve the problem of steering operation during low speed driving. Mechanical Engineering Journal, 2019, 6(3): 18-00386.

[10] Y Yin, S Rakheja, J Yang, et al. Design optimization of an articulated frame steering system. Proceedings of the Institution of Mechanical Engineers, Part D: Journal of Automobile Engineering, 2018, 232(10): 1339-1352.

[11] B W Cao, X H Liu, W Chen, et al. Depth optimization analysis of articulated steering hinge position based on genetic algorithm. Algorithms, 2019, 12(3): 55.

[12] AMICO D A. Pressure control in hydraulic power steering systems: division of fluid and mechatronic systems. Sweden: Linköping University. 2013: $14-22$.

[13] S Haggag, D Alstrom, S Cetinkunt, et al. Modeling, control, and validation of an electro-hydraulic steer-by-wire system for articulated vehicle applications. IEEE/ASME Transactions on Mechatronics, 2005, 10(6): 688-692.

[14] K Heybroek, J Larsson, J O Palmberg. Mode switching and energy recuperation in open-circuit pump control. Tampere, Finland: Tampere Univ. Technol., 2009: 197-209.

[15] N A Daher, M Ivantysynova. Energy analysis of a traditional steering technology that saves fuel and boosts efficiency. Energy Conversion and Management, 2014, 86: 1059-1068.

[16] N A Daher, M Ivantysynova. Pump controlled steer-by-wire system. SAE Technical Papers, 2013: 7.

[17] N A Daher. New steering concept for wheel loaders. The 9th International Fluid Power Conference, Aachen, Germany, March 24-26, 2014: 112-117.

[18] G P Massarotti. Hydrostatic steering system and energy saving evaluation in idle regime. 10th JFPS International Symposium on Fluid Power, Fukuoka, Octorber 24-27, 2017: 2A11-1-2A11-7.

[19] Y Yang, G Zhang, J Zha, et al. Design of automatic steering system based on direct connection of DC motor and full hydraulic steering gear. Transactions of the Chinese Society for Agricultural Machinery, 2020, 51(8): $44-54+61$.

[20] J Wang, P Hou, H Cai, et al. Continuous angle steering of an opticallycontrolled phased array antenna based on differential true time delay constituted by micro-optical components. Optics Express, 2015, 23(7): 9432.

[21] L He, B Ma and C Zong. Fault-tolerance control strategy for the steering wheel angle sensor of a steer-by-wire vehicle. Chinese Journal of Automotive Engineering, 2015, 37(3): 327-330, 345.

[22] W Z Zhao, Y J Li, CY Wang. Robust control of hand wheel torque for active front steering system. Science China Technological Sciences, 2015, 58(1): 107-116. 
[23] M Khristamto, A Praptijanto, S Kaleg. Measuring geometric and kinematic properties to design steering axis to angle turn of the electric golf car. Energy Procedia, 2015, 68(1): 463-470.

[24] A Dellamico, P Krus. Modeling, simulation, and experimental investigation of an electrohydraulic closed-center power steering system. IEEE/ ASME Transactions on Mechatronics, 2015, 20(5): 1-11.

[25] XYTian, ZC Yu, H Zhou, et al. The design research of the indigenous steering gear. 2016 Chinese Control and Decision Conference (CCDC) IEEE, 2016 6947-6952.

[26] L H Liang, L Y Wang, J F Wang. Energy-saving nonlinear friction compensation method for direct drive volume control flange-type rotary vane steering gear. IEEE Access, 2019, 7:15851-62.

[27] L Liang, L Wang, J Wang. The compensation for nonlinear friction of DDVC flange-type rotary vane steering gear. PLOS ONE, 2018, 13(11): e0207018.
[28] A DellAmico, P Krus. Modeling, simulation, and experimental investigation of an electrohydraulic closed-center power steering system. IEEE/ ASME Transactions on Mechatronics, 2015, 20(5), 2452-2462.

[29] Q Q Lu. Simulation analysis and test of full hydraulic steering system for flow amplification. Hangzhou: Zhejiang University, 2010. (in Chinese)

[30] X H Liu, Q W Li, J S Chen, et al. Mathematical modeling and simulation of load - sensing priority valve. Journal of Jilin University (Engineering \& Engineering Edition), 2015, 45(6): 1817-1824.

[31] B Hu, C J Zhou, H B Wang, et al. Prediction and validation of dynamic characteristics of a valve train system with flexible components and gyroscopic effect. Mechanism and Machine Theory, 2021, 157: 104222.

\section{Submit your manuscript to a SpringerOpen ${ }^{\odot}$ journal and benefit from:}

- Convenient online submission

- Rigorous peer review

- Open access: articles freely available online

- High visibility within the field

- Retaining the copyright to your article

Submit your next manuscript at springeropen.com 